\title{
Seepage in Water-Rich Loess Tunnel Excavating Process and Grouting Control Effect
}

\author{
Zhengde Wei (iD) and Yanpeng Zhu \\ School of Civil Engineering, Lanzhou University of Technology, Lanzhou, Gansu 730050, China \\ Correspondence should be addressed to Zhengde Wei; 382526552@qq.com
}

Received 31 January 2021; Revised 22 February 2021; Accepted 3 March 2021; Published 22 April 2021

Academic Editor: Bin Gong

Copyright () 2021 Zhengde Wei and Yanpeng Zhu. This is an open access article distributed under the Creative Commons Attribution License, which permits unrestricted use, distribution, and reproduction in any medium, provided the original work is properly cited.

\begin{abstract}
The tunnel passing through the loess stratum with high moisture content can easily lead to the seepage and mud burst accident and the instability and collapse of the tunnel face. Under the condition of high groundwater level, the seepage situation is more complicated, it is difficult to control the groundwater seepage, and the excavation progress is very slow. In order to solve the various disasters when the tunnel passes through the water-rich loess stratum, taking a water-rich loess tunnel in Gansu Province as an example, the method of comprehensive prevention and control of seepage and mud inrushing disaster by basement grouting and curtain grouting was introduced. Firstly, the basic situation of the Yulinzi tunnel is introduced, including site conditions, seepage collapse accident, and its cause analysis. On this basis, the design and construction methods of basement grouting and curtain grouting are introduced, and the effect of grouting reinforcement is evaluated in detail through on-site monitoring. The results show that the basement grouting and curtain grouting can effectively control the deformation of surrounding rock and the surface settlement, the decrease of the deformation of surrounding rock can reach $36 \%-71 \%$, and the decrease of the surface settlement can reach 55\%. After grouting, the deformation of the surface and surrounding rock can be controlled within the allowable value in the code. Grouting plus solid can effectively block the seepage of groundwater and prevent the surface cracks, water gushing, mud gushing, collapse, and other disasters in the process of tunnel excavation. It can be seen that the basement grouting combined with curtain grouting technology has a good reinforcement effect, which has significant engineering value for quickly and efficiently passing through high moisture content loess strata.
\end{abstract}

\section{Introduction}

In recent years, with the development of western China and the in-depth deployment of "One Belt And One Road" strategy, a large number of highways and railways will be crossing the loess area, and the loess tunnel will increase accordingly. Compared with other types of tunnels, geological disasters such as collapse, water gushing, and large deformation are particularly prominent in loess tunnels $[1,2]$. When tunneling in a water-rich loess stratum, the groundwater will percolate due to the difference of water head inside and outside the tunnel. The seepage of groundwater can easily lead to the instability of water inrush and mud surge on the tunnel face and accelerate the consolidation and settlement of the stratum, and the excessive deformation of the stratum settlement may even cause tunnel collapse accidents [3-6]. For example, on March 18, 2011, a large area of tunnel No. 1 collapsed during construction in Dongchuan, Shanxi Province, resulting in 3 casualties. The main cause of the accident was the thawing of permafrost on the vault surface of the tunnel, and the seepage caused by meltwater from ice and snow resulted in serious subsidence and deformation of the ground. On April 20,2011, there were 12 casualties in a similar seepage collapse at a tunnel in Xiaoping Qiang, Gansu Province. Therefore, the construction of a loess tunnel in the water-rich area has become an important factor restricting the construction progress, construction safety, and environmental protection of tunnel engineering.

At present, in view of the rich water area tunnel surface subsidence and deformation of the surrounding rock of main control measures for the improvement of construction technique, such as adopting three-step reserved core geotechnical 
method, double side heading method, etc., and supporting measures such as strengthening of the advanced small pipe [7-11]. However, these measures to control the deformation of tunnel surrounding rock vault subsidence and horizontal convergence have good effect, but not outside the tunnel excavation contour forming an effective reinforcement ring; it is difficult to ensure construction safety and the treatment effect is not ideal.

Grouting water plugging and reinforcing stratum is an effective method to overcome the influence of groundwater on engineering construction and is the most commonly used method among many groundwater control measures. Scholars have done in-depth research on grouting reinforcement of water-rich tunnels. In the aspect of experimental research, Modoni et al. [12] studied the single and double fluid jet grouting technology in sandy soil and cohesive soil through field test. Gong et al. [13] proposed that multiple grouting methods could better control seepage and rock mass deformation. Bohloli et al. [14] studied the flow and mechanical properties of different types of cement slurry at actual tunnel temperature and room temperature. Zhu et al. [15] studied the diffusion mechanism of grouting by using a one-dimensional permeability grouting test method of constant flow sand column. Taking the tunnel construction stage as an example, Lisa et al. [16] proposed a decision-making method to determine whether grouting was needed. In terms of surface grouting, $\mathrm{Xu}$ et al. [17] used an orthogonal test method to study three grouting materials and 36 grouting ratios in the laboratory and found the grouting materials and reasonable grouting ratio suitable for surface grouting in a shallow buried section. Wisser et al. [18] described the numerical model method of compensation grouting and proposed a useful technology to protect the surface structure from the potential damage caused by tunnel construction. Türkmen and Özgüzel [19] introduced the treatment measures of contact grouting and consolidation grouting in the collapse of irrigation tunnel excavation. The existing research results mainly focus on the effect analysis of surface grouting, and these measures have good effect on controlling surface settlement, but poor effect on controlling tunnel surrounding rock vault settlement and horizontal convergent deformation. The most important thing is that vertical surface grouting is only applicable to tunnels with relatively shallow buried depth (less than $50 \mathrm{~m}$ ), but not for deep tunnels.

At present, tunnel curtain grouting technology has been widely used. Liu et al. [20] introduced the method of using curtain grouting to prevent water and mud inrush disaster in a weathered layer. Through numerical and experimental data analysis, Contini et al. [21] proposed that applying neutral pressure in the grouting area is more suitable for estimating surface displacement caused by field engineering. Brantberger et al. [22] put forward the concepts of a normalised pressure and normalised grout spreading and discussed the potential uses of the theory. Liu et al. [23] proposed a seepage erosion coupling water inrush model and studied the seepage erosion characteristics. Jin et al. [24] adopted the method of combining the grouting protection method in the tunnel with the shield method, which greatly reduced the influence on the existing tunnel when the double tunnels were built underground. The above research results mainly focus on the effect analysis of curtain grouting in medium and small section tunnels, and the soil is mostly rock or soft soil.

Recently, scholars have also conducted in-depth research on grouting effect evaluation [25-28]. In addition, some exploration has been carried out on the grouting reinforcement of a water-rich loess tunnel. Qiu et al. [29] studied the long-term settlement performance of a loess tunnel reinforced by a vertical jet grouting pile. Li et al. [30] studied the reinforcement effect of a high-pressure jet grouting pile in a collapsible loess tunnel foundation of a deep buried long-span tunnel through field displacement and stress monitoring. Wang et al. [31] analyzed the diffusion mechanism of grouting in the collapsible loess stratum in view of the water inrush disaster of the tunnel. At present, whether curtain grouting reinforcement technology is feasible for a long section and large span deep buried loess tunnel and the grouting effect still needs more practical verification and in-depth analysis.

The background of this paper is a seepage collapse accident in a loess tunnel in Qingyang City, Gansu Province. Firstly, the general situation of the project is introduced, and then the accident of collapse and roof collapse and the treatment measures are described systematically, and the square reason of seepage collapse is analyzed. On this basis, the design and construction methods of basement grouting and curtain grouting are introduced, and the effect of grouting reinforcement is evaluated in detail through on-site monitoring, in order to provide a practical basis for the safety construction and deformation control of a water-rich loess tunnel and the provide reference for similar engineering design.

\section{Engineering Background and Seepage Collapse Accident}

2.1. Background of the Yulinzi Tunnel. Qingyang City is located in the southeast of Gansu Province, China. The Yulinzi tunnel is a part of the Yin-Bai Expressway Project in Qingyang City. The tunnel is located $2200 \mathrm{~m}$ west of Yulinzi Town, Zhengning County, Qingyang City, as shown in Figure 1(a). The total length of the tunnel project is about $1970 \mathrm{~m}$, which is a single hole and double track tunnel. The elevation of the tunnel is $1170.00-1294.00 \mathrm{~m}$, and the relative height difference is $124.00 \mathrm{~m}$. There are loess gullies developed at the entrance and exit, and the gullies are narrow, and the slope is steep. The maximum buried depth is $113 \mathrm{~m}$, as shown in Figure 1(b). The lithology of the tunneling site is the Quaternary Upper Pleistocene $\left(\mathrm{Q}_{3}{ }^{\text {eol }}\right)$ Malan loess and Middle Pleistocene $\left(\mathrm{Q}_{2}{ }^{\mathrm{eol}}\right)$ Lishi loess with multiple layers of paleosol.

The stratum through which the tunnel passes is the Longdong Loess Plateau, the largest loess region in the world, which is characterized by a simple regional geological structure, the development of vertical loess joints, and the development of irregular tensile joints locally. The width of the fissure is large, more than $1 \mathrm{~cm}$, and it is a channel for the infiltration of meteoric water. In fact, dense vegetation can 


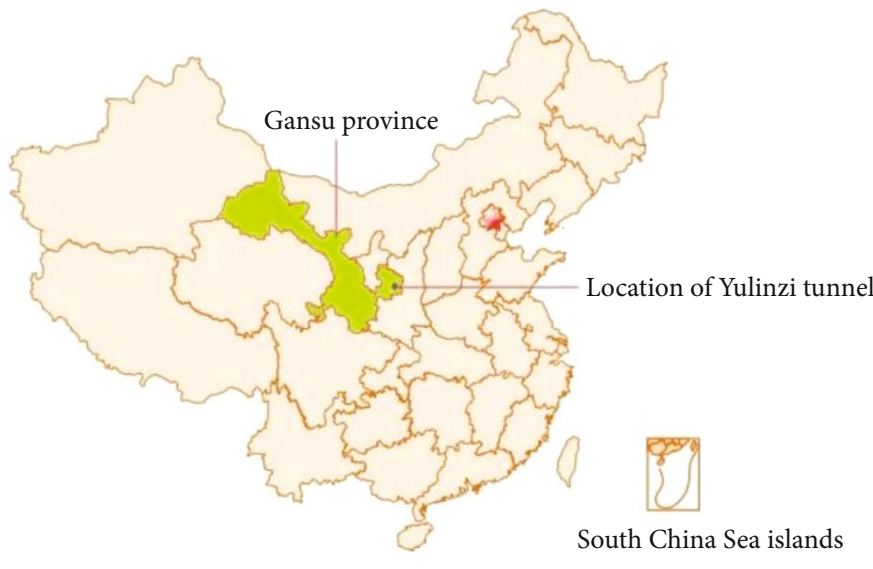

(a)

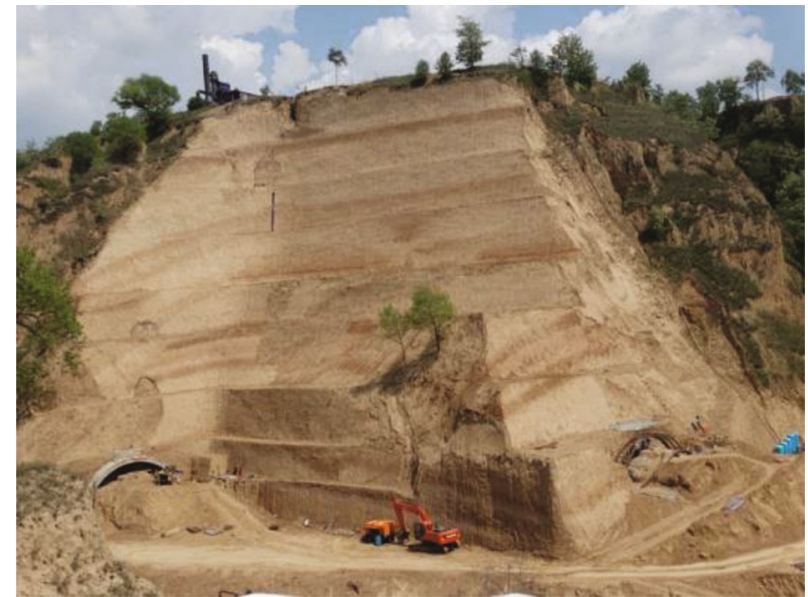

(b)

FIGURE 1: Location and surrounding geological conditions of Yulinzi tunnel.

be observed on the surface of the tunnel in this area. More importantly, the groundwater in the tunnel site area is pore water of loose rock, and the tunnel is located below the underground water level. The water content of the surrounding rock in the construction section is too high, the water seepage at the face of the tunnel is serious, and there is a water gushing and mud gushing phenomenon, which usually hampers the construction of the tunnel (see Figure 2). Considering the influence of groundwater seepage, in order to ensure the construction safety, the New Austrian Tunnelling Method excavation is adopted in the process of tunnel construction, and drainage measures are strengthened. However, the seepage collapse accident occurred at the tunnel face $1893 \mathrm{~m}$ away from the opening of the portal (see Figure 3).

2.2. Collapse Accident. On the evening of December 19, 2019, the arch of YK280+596.8 at the right exit of the Yulinzi tunnel collapsed, and then the upper and middle steps of YK280 +596.8 to YK280+617.6 on the tunnel face collapsed after the initial support failure. After the collapse, the soil gushing out caused the sections of YK280+617.6 to YK280+630.8 to collapse without the construction of secondary lining filling and pushed the secondary lining trolley and the waterproof plate working trolley to the direction of the entrance for about $15 \mathrm{~m}$, as shown in Figure 4. The tunnel in this section is buried to about $95 \mathrm{~m}$. At the surface of YK280+600 corresponding to the tunnel collapse is a surface pit with a diameter of about $38 \mathrm{~m}$, with a peripheral staggered platform of about $2 \mathrm{~m}$ and central depth of about $8 \mathrm{~m}$ (see Figure 5). After the collapse occurred, the construction personnel and machinery in the tunnel were evacuated in time, and the corresponding position of the roof was set up with warning lines to ensure the safety of construction. According to the situation of the site, the preliminary disposal scheme is put forward.

2.3. Disposal Measures. Subsequent collapse treatment measures are as follows: (1) For the pit at the bottom of the surface, $5 \%$ lime soil is used for backfilling, leveling, and compaction, and the compaction degree reaches more than
$90 \%$. Then, the surface is backfilled with $1 \mathrm{~m}$ thick planting soil, and the soil body is slightly higher than the surrounding surface after backfilling, so as to prevent the infiltration of surface water. (2) The collapsed soil mass flowing into the constructed secondary lining section is repaired, a wall for grouting and a $20 \mathrm{~m}$ long drain hole are set up, and the collapsed section of YK280+625-YK280+617.6 is timely backfilled with back pressure to prevent further expansion of collapse. (3) Surface well point precipitation is adopted for this section to reduce water content of surrounding rock and groundwater level in the tunnel. (4) Construction of grouting small conduit on the section of the collapse in the cave to reinforce the collapse in the cave. After the completion of the grouting, the collapse is repaired and the construction platform is gradually completed. (5) After the repair and reinforcement of the cave collapse, a $2 \mathrm{~m}$ thick cast-in-place concrete wall for grouting was built at YK280+628 and YK280+611, and the collapse was reinforced by advanced high-pressure grouting. (6) Temporary reinforced arches were added at the end of the lining, and the ring grouting was carried out to reinforce the surrounding rock. The whole process of rescue was tracked and monitored.

\subsection{Causes of the Accident}

2.4.1. The Complex Engineering Geological Conditions Cause the Instability of the Engineering Structure. The accident occurred in the layered Paleozoic strata of the Lishi loess. Due to the development of the vertical joints of the loess, the vertical weak surface was formed due to the cutting of the joints. After the tunnel was excavated, it was easy to collapse along the soft surface, and the collapse was often abrupt. At the same time, the water content of the tunnel surrounding rock is large, and the seepage flow of the tunnel face and vault is high, which leads to the continuous loss of soil particles in the vault, the softening of the soil in the roof of the tunnel, and the continuous increase of pressure in the surrounding rock. The influence of groundwater on the surrounding rock of loess easily causes plastic deformation or disintegration of the 


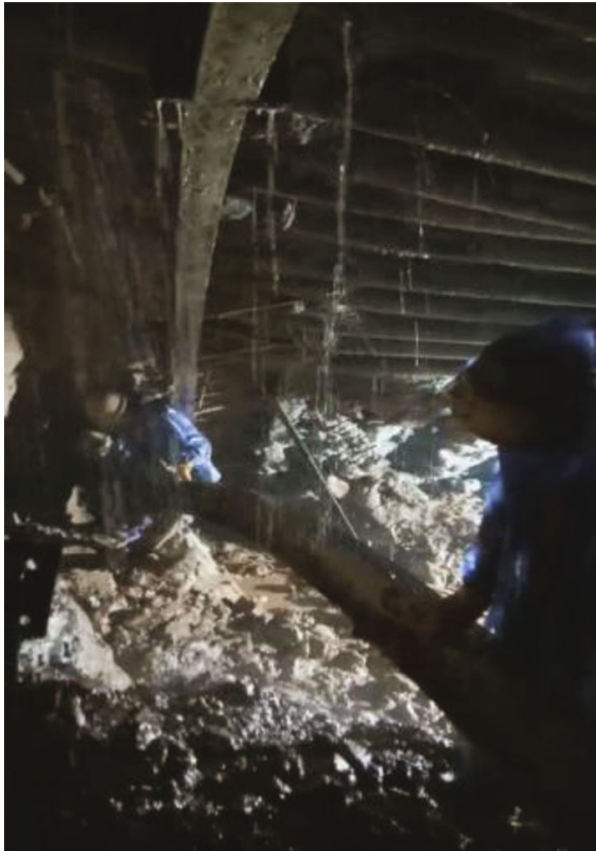

(a)

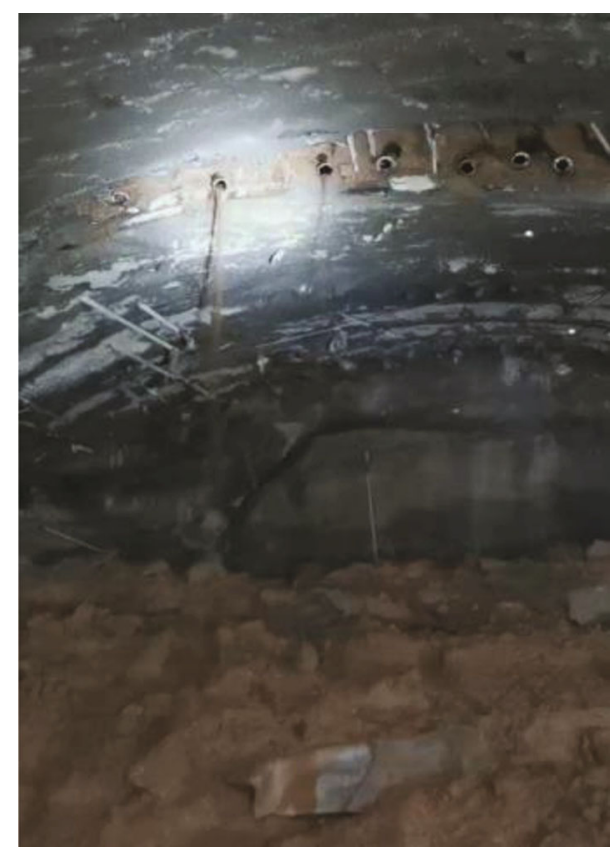

(b)

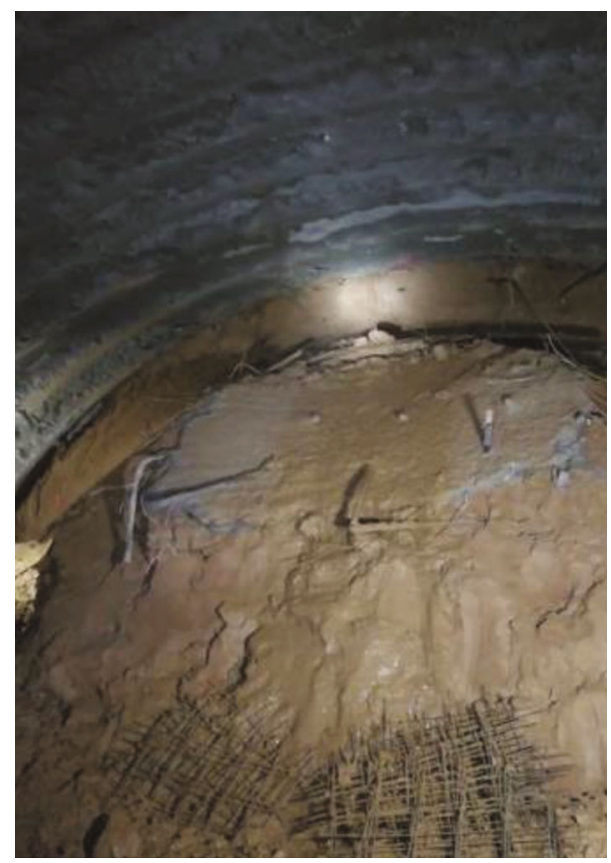

(c)

FIGURE 2: Water gushing and mud inrush at tunnel face: (a) tunnel water gushing; (b) water inrush from advance pipe shed; (c) mud burst on tunnel face.

surrounding rock, resulting in collapse near the tunnel face and a large number of collapse soils gushing out. Therefore, the poor geological structure of the site is the main cause of the collapse accident.

\subsubsection{Groundwater Seepage Accelerates Formation} Consolidation and Deformation. The seepage disaster of the loess is studied deeply, and the analysis results show that the physical and mechanical properties of loess and hydrological conditions play a key role in the occurrence of the roof caving disaster. Due to the formation of seepage surface in the excavation of water-rich loess stratum, groundwater seepage occurs under the action of water head difference. The pore water pressure of soil decreases, the water level of the overlying strata of the tunnel decreases, and the effective stress of the stratum increases, which 


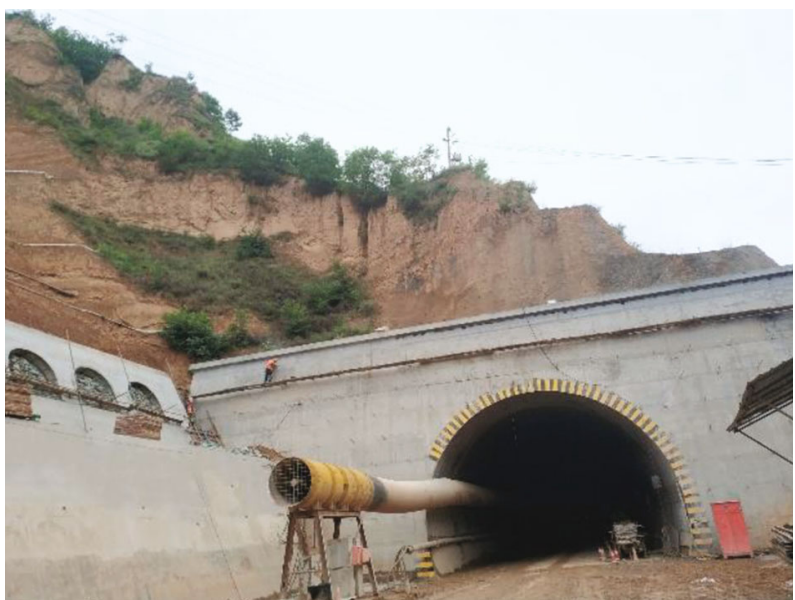

(a)

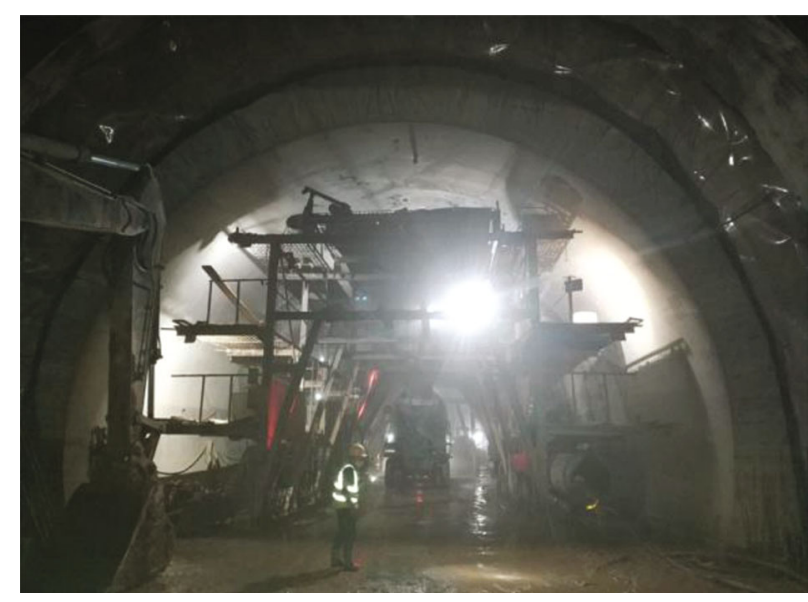

(b)

FIgURE 3: Construction situation (a) outside and (b) inside the tunnel before the incident.

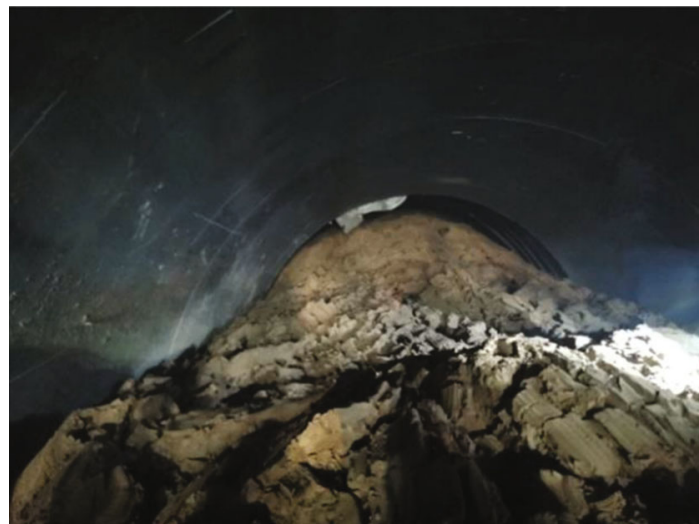

(a)

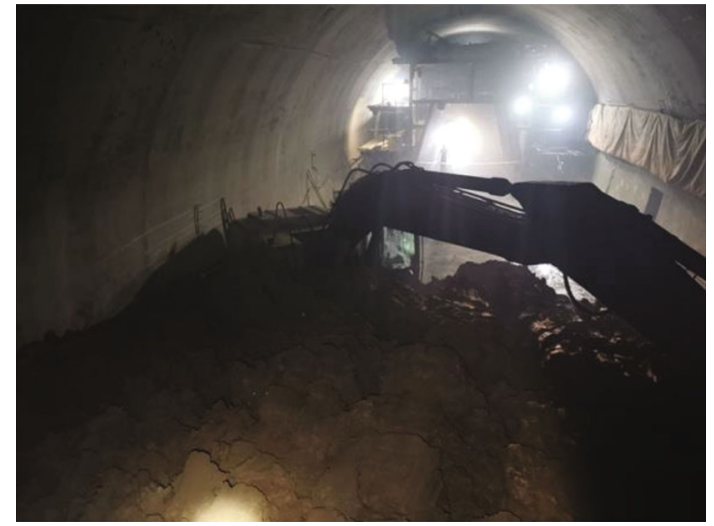

(b)

Figure 4: Accident scene: (a) collapse and mud bursting in tunnel; (b) excavator flushed away by inrush mud.

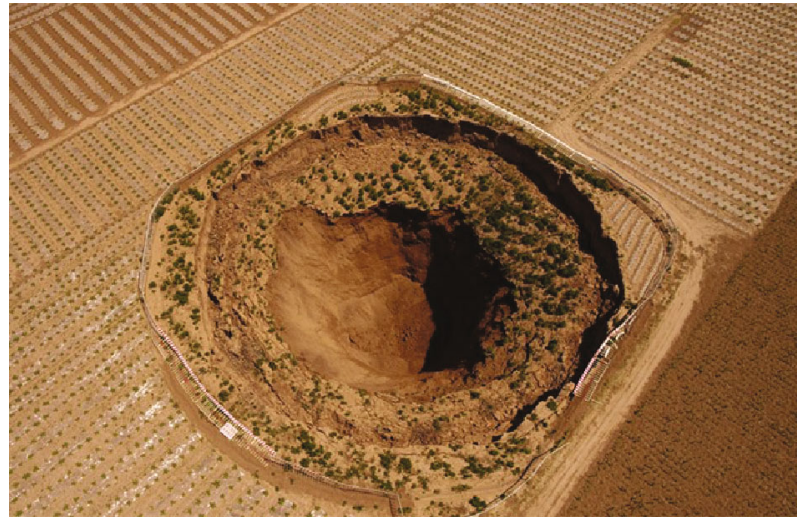

FIGURE 5: Large scale surface subsidence occurred.

accelerates the consolidation deformation of soil. On the one hand, it causes the vault settlement; on the other hand, it also causes the basement uplift deformation and then leads to the instability of the tunnel.

\section{Grouting Design of the Yulinzi Tunnel}

3.1. Grouting Mechanism. In the process of tunnel engineering grouting construction, due to the different geological conditions, geological media, and grouting materials, the grouting may show different diffusion mechanisms in the formation reinforcement and water plugging, which are mainly manifested in four kinds: permeation diffusion, splitting diffusion, fissure filling, and disturbance displacement compaction [32], as shown in Figure 6.

The main engineering properties of loess are as follows: the composition is dominated by silt particles, the structure is uniform without bedding, the soil is loose, and the compressibility is medium to high. In the loess, the vertical joints and fissures are developed, and the water absorption of the silt is poor and the permeability is good. In the dry state, the skeleton particles of loess are the backbone of the spatial structure system of loess, and the skeleton particles are aggregated with various cementing materials at the contact point to form a cementing bond, which has good mechanical strength. With the increase of the moisture content of loess, 


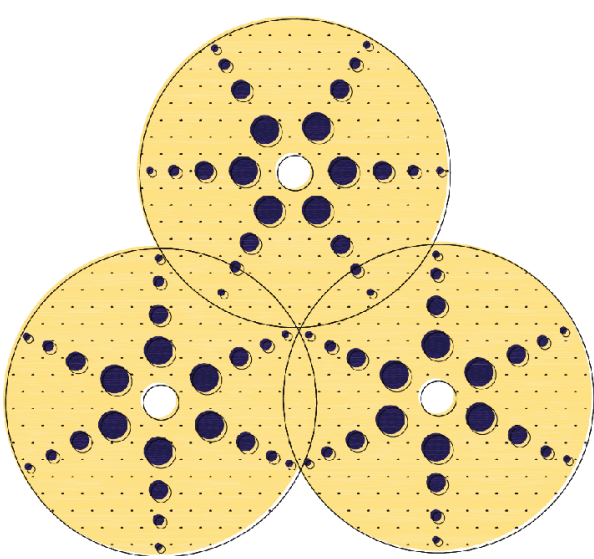

(a)

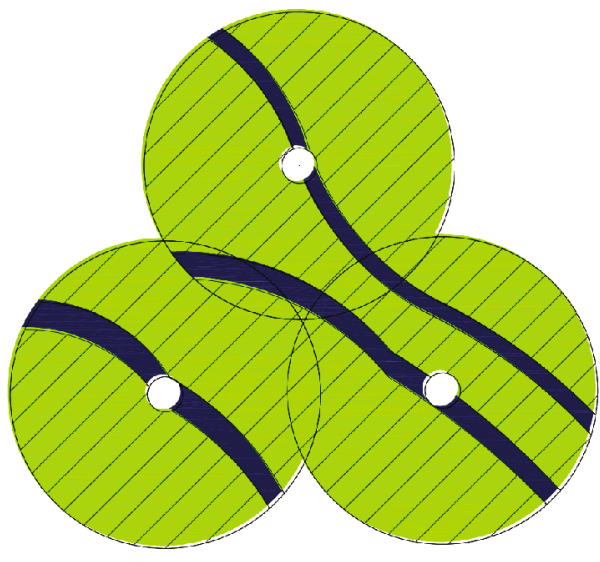

(c)

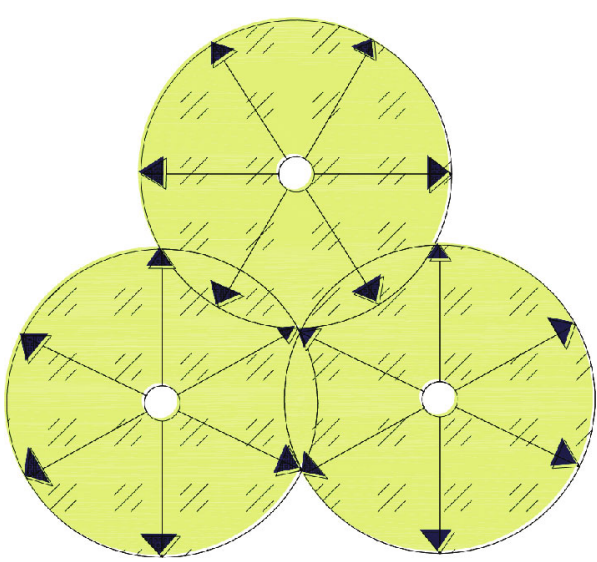

(b)

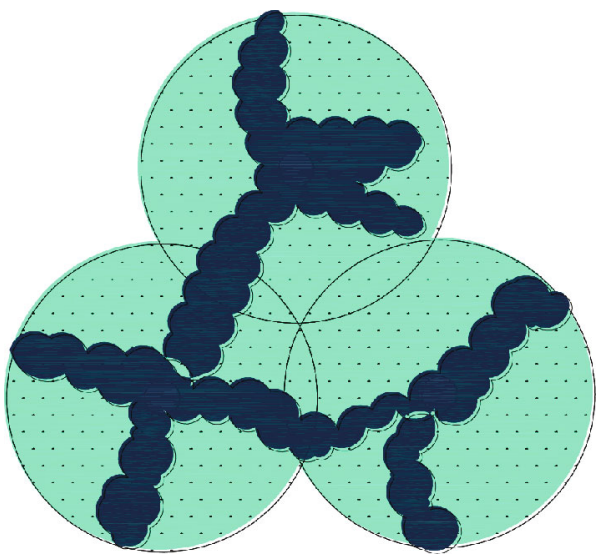

(d)

FIGURE 6: Diffusion mechanism model of grouting in stratum: (a) permeation diffusion; (b) splitting diffusion; (c) fissure filling; (d) disturbance displacement compaction.

water will soften and partially dissolve the cements at the contact parts of particles, weaken the structural connection, and significantly reduce the mechanical strength of soil, and then collapse accident occurs [33]. By the grouting amount of pore water in the loess, the grouting pressure exceeds the limit of the soft loess strata shearing resistance, the soft loess stratum splits apart, and the grout along the cleavage surface infiltration and formation compaction forms a mesh split pulse, to strengthen the mechanical properties and impervious soil and achieve the goal of grouting reinforcement and water plugging. Therefore, the grouting mechanism of the loess stratum belongs to splitting diffusion.

3.2. Grouting Reinforcement Scheme. At present, grouting reinforcement methods for tunnel water shutoff include horizontal advance grouting in tunnel (curtain grouting), vertical grouting on the tunnel surface, tunnel basement grouting, tunnel radial grouting, horizontal rotary jet grouting, and so on.

During the excavation of the Yulinzi tunnel, the water content of the tunnel face increased significantly, with the maximum value reaching $29.9 \%$. The water gushing and mud bursting phenomenon occurred in some parts of the tunnel. The properties of surrounding rock were poor, and the vault fell continuously, collapsed, and formed a large cav- ity. The grouting of a large pipe shed and a small conduit in advance is adopted to reinforce the surrounding rock, but the treatment effect is not ideal, and the effective reinforcement circle cannot be formed outside the contour of tunnel excavation, so it is difficult to ensure the safety of construction. Considering the large buried depth of the Yulinzi tunnel, if the surface grouting method is adopted, the grouting hole depth is about $100 \mathrm{~m}$, which has problems such as long construction period, high cost, difficult land acquisition, and verification of the grouting effect. Therefore, in order to effectively control the deformation of tunnel surrounding rock and the surface settlement deformation and enhance the stability of the soil within the influence range of excavation, the comprehensive reinforcement scheme of basement grouting and curtain grouting was adopted for the Yulinzi tunnel YK280+455-YK280+400 section (the thickness of vault overlaying soil is about $100 \mathrm{~m}$ ). The treatment measures are as follows.

3.2.1. Basement Grouting Reinforcement Scheme. The tunnel basement grouting is usually arranged on the surface of the invert or the filling layer, and the rigid grouting pipe is installed in the grouting hole. The grouting steel pipe can also form the composite foundation of the steel pipe pile with the reinforced stratum. The advantages of the tunnel basement 


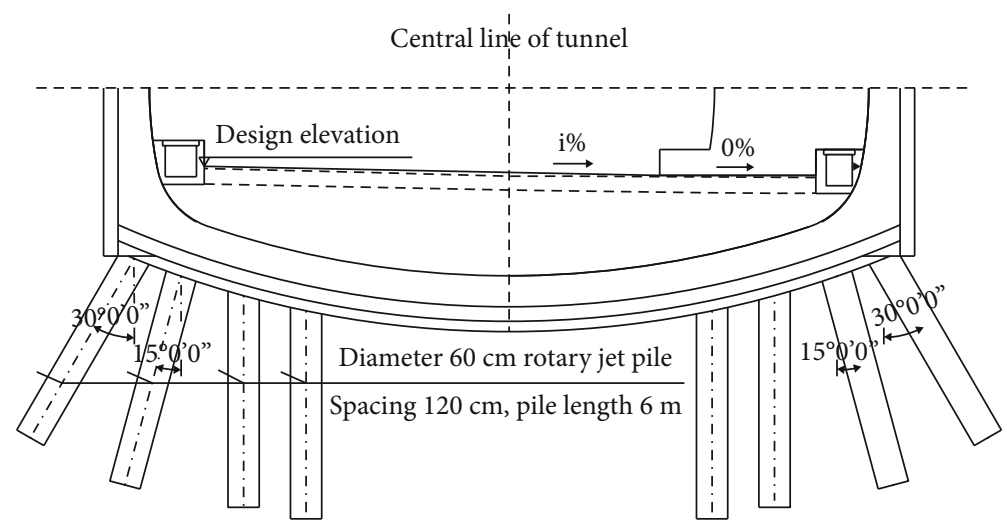

FIgURE 7: Cross-section of foundation treatment at invert bottom of tunnel.

grouting are as follows: one is to improve the bearing capacity of the basement and the other is to block water and reduce water pressure and water softening to the stratum.

Invert wall foundation of the right line YK280+455YK280+400 section was reinforced by grouting of the rotary jet pile with a length of $55 \mathrm{~m}$. Design parameters are as follows: diameter $0.6 \mathrm{~m}$, pile length $6 \mathrm{~m}$, spacing $1.2 * 1.2 \mathrm{~m}$, and staggered layout. Grouting parameters are as follows: the grouting slurry was cement slurry with a water-cement ratio of $1: 1$. The grouting pressure was $0.5-1.0 \mathrm{MPa}$ for the initial pressure and 3.0 MPa for the final pressure. Grouting field test should be carried out before grouting, and the grouting parameters should be determined according to the actual situation through a field test. Jet grouting pile shall be constructed before invert excavation. Figures 7 and 8 are schematic drawings of cross-section and plane layout of basement grouting, respectively.

3.2.2. Curtain Grouting Reinforcement Scheme. The curtain grouting longitudinal reinforcement length of the right line is $55 \mathrm{~m}$. Cast-in-place C30 concrete wall for grouting with a thickness of $2 \mathrm{~m}$ was built at YK280+455 and YK280+430, and the surrounding rock outside the contour line of the cave was strengthened by advanced high-pressure grouting. The rig operating platform is $5 \mathrm{~m}$ long and $20 \mathrm{~cm}$ thick with C30 concrete.

The grouting parameters are designed as follows: (1) The advance curtain grouting section is divided into two cycles, the length of each cycle is $30 \mathrm{~m}$, and $5 \mathrm{~m}$ is overlapped between the two cycle grouting sections, with a total length of $55 \mathrm{~m}$. The reinforcement scope shall be controlled $5 \mathrm{~m}$ outside the upper excavation contour to ensure construction safety and prevent the face from collapsing due to water gushing. (2) According to the formation characteristics, grouting materials, and water plugging requirements, the grouting hole slurry diffusion radius is selected as $2 \mathrm{~m}$ by engineering analogy method. According to the requirement that no "grouting blind area" occurs in the section of the final hole of the grouting curtain, the overlap between the grouting holes should be compact, and the distance between the final hole of the grouting should be $1.5 R$ ( $R$ is the slurry diffusion radius), and the distance between the final hole of the grouting should be calculated to be about $3 \mathrm{~m}$, which meets the

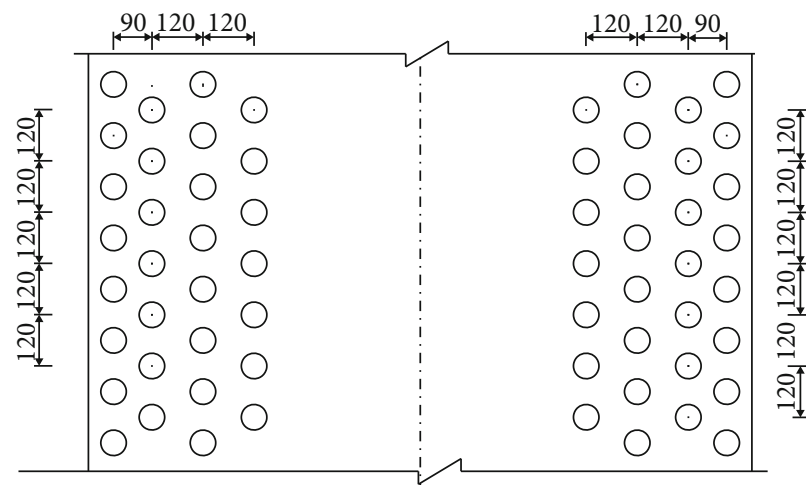

Figure 8: Schematic diagram of basement grouting layout (units: $\mathrm{cm})$.

design requirements. (3) Common Portland cement and sodium silicate double slurry are used as grouting material, and the water-cement ratio of the slurry is $\mathrm{W}: \mathrm{C}=0.8-1$ $: 1, C: S=1: 0.8$, or the water-cement ratio of cement slurry is $1: 1 \sim 0.8: 1$. The modulus of sodium silicate is $2.5-2.8$, and Baumé degree is $38^{\circ}$ Bé. (4) According to the effect analysis of the grouting test section, the grouting pressure of $4-6 \mathrm{MPa}$ is more appropriate, and the final pressure is $6.0 \mathrm{MPa}$. The layout of the curtain grouting holes is shown in Figures 9, 10, and 11 .

\section{Analysis of Grouting Reinforcement Effect}

4.1. Deformation Analysis of Tunnel Surrounding Rock. Figure 12 shows the comparison curves of surrounding rock vault settlement, horizontal convergence, and inverted arch displacement before and after basement grouting combined with curtain grouting at adjacent sections. As can be seen from Figure 12, after excavation of nongrouting sections YK280+470, surrounding rock vault settlement, horizontal convergence, and inverted arch displacement vary greatly, experiencing a basic linear growth stage and a nonlinear transition stage. The turning point occurred about 11 days after the excavation of the upper step, the vault settlement reaches $78.6 \mathrm{~mm}$, and the uplift deformation of the inverted arch reached $105.4 \mathrm{~mm}$. At this time, the deformation was not stable, and the deformation of surrounding rock 


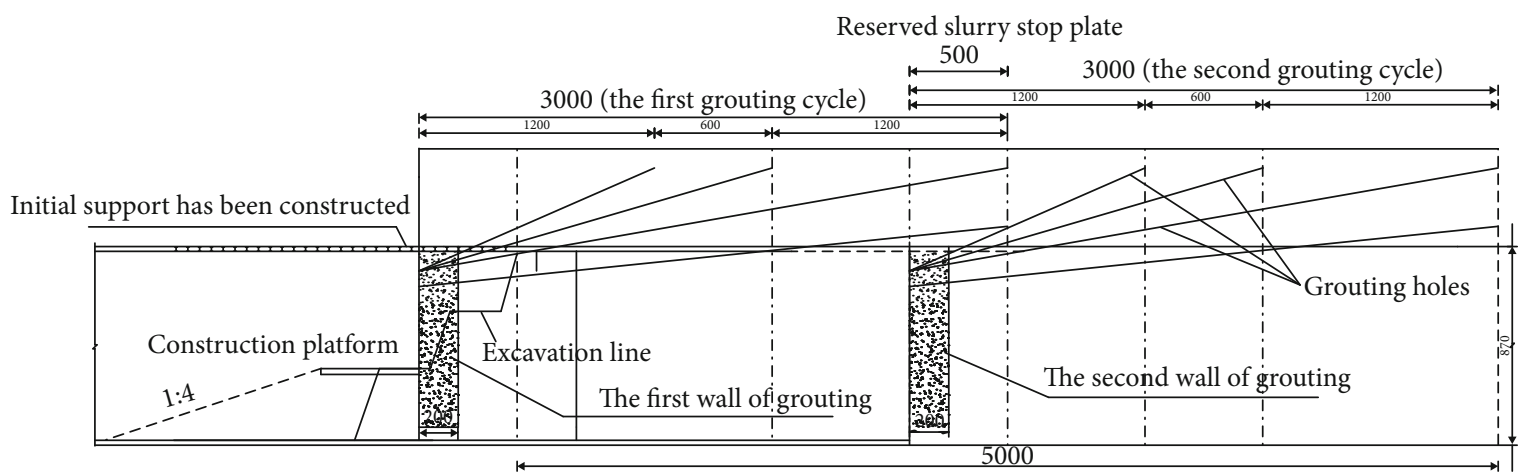

FIGURE 9: Vertical section of grouting (units: $\mathrm{cm}$ ).

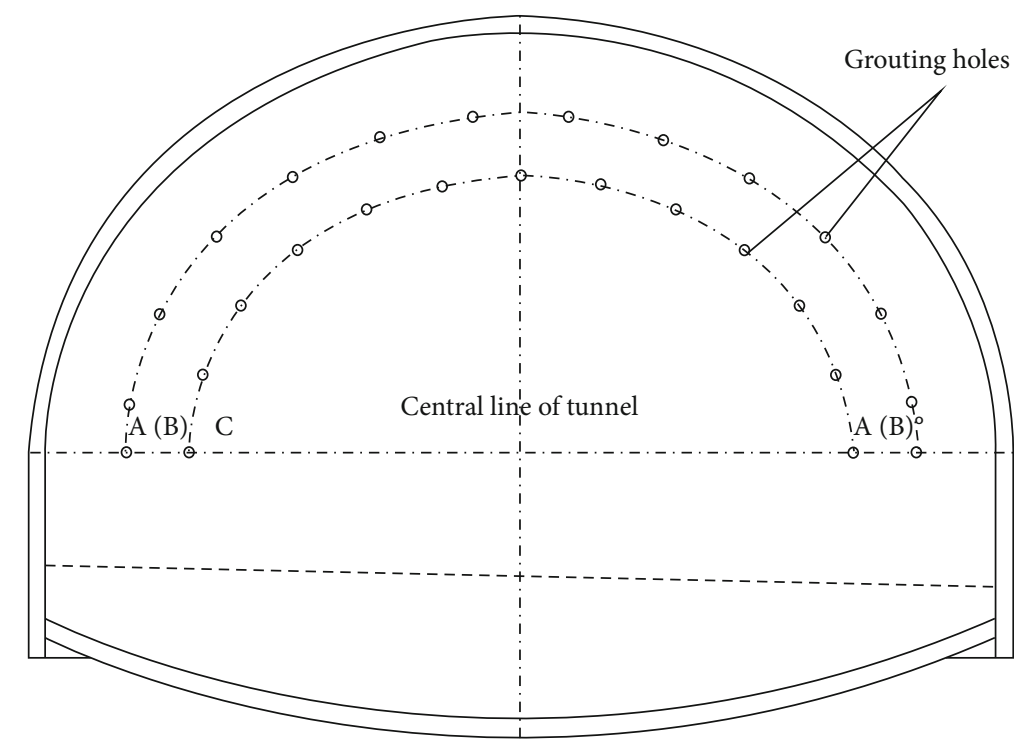

(a)

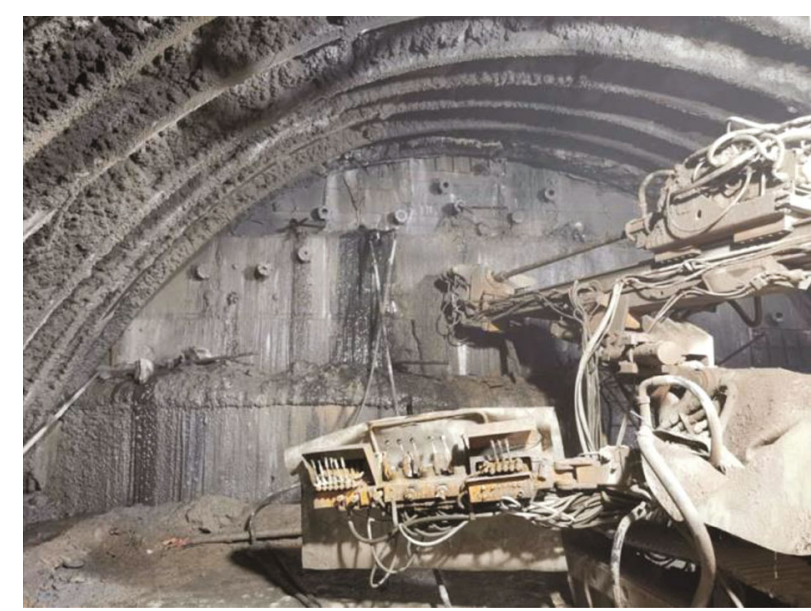

(b)

FIGURE 10: Curtain grouting construction: (a) layout of grouting hole; (b) construction site of curtain grouting.

continued to increase nonlinearly. After 30 days, the maximum values of the three are $109.3 \mathrm{~mm}, 51.7 \mathrm{~mm}$, and $163.3 \mathrm{~mm}$, respectively. According to the relevant provisions of the code [34], the deformation amount has exceeded the allowable value of the displacement control benchmark, and deformation control measures should be taken.

However, for the sections YK280+450 reinforced by basement grouting combined with curtain grouting, the vault 


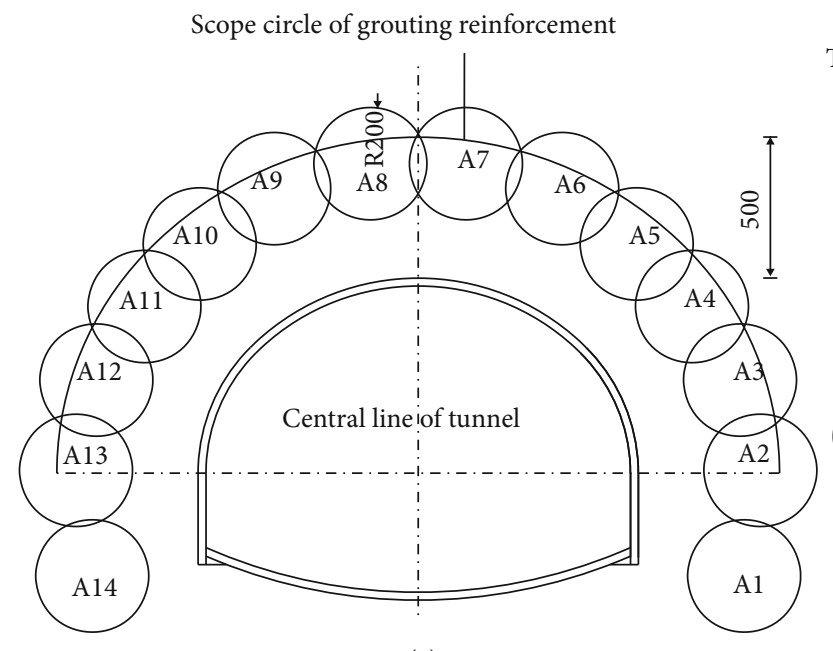

(a)

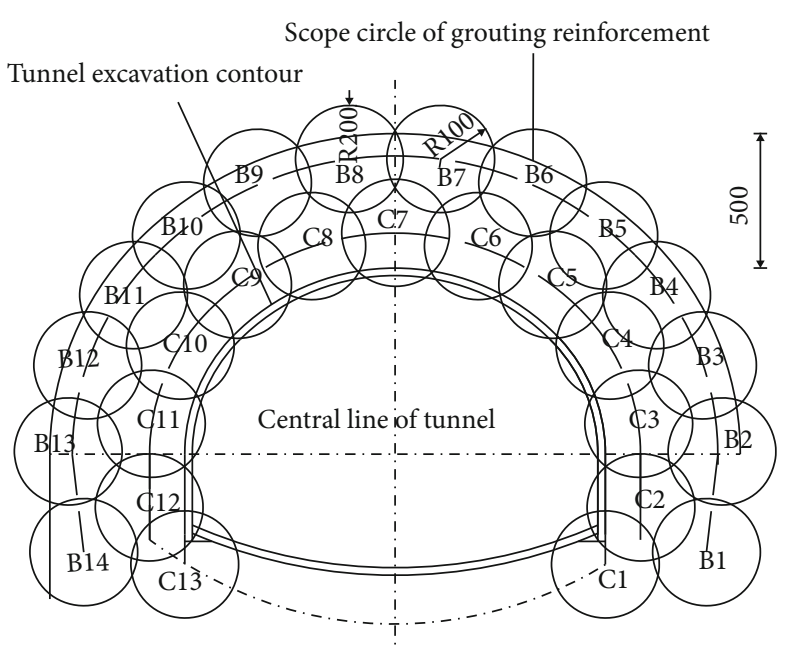

(b)

FIGURE 11: Schematic diagram of hole cross-circle: (a) the middle section; (b) the final section (units: $\mathrm{cm}$ ).

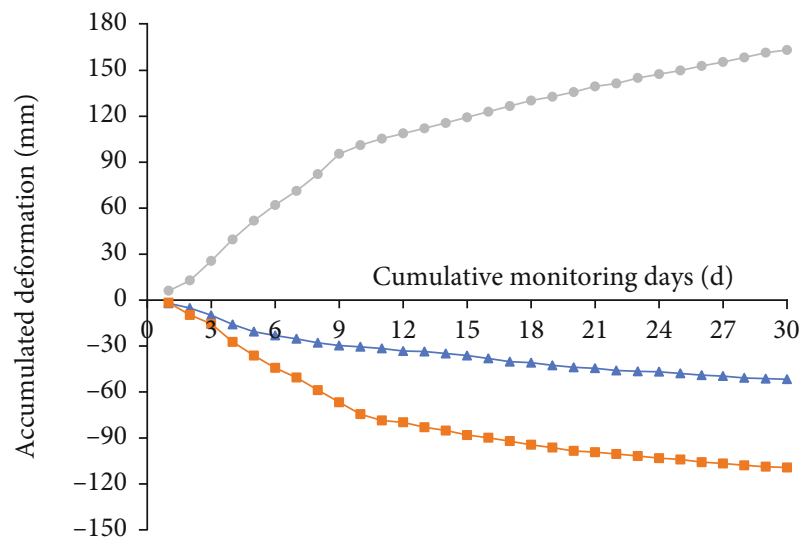

(a) Sections YK280+470 without grouting

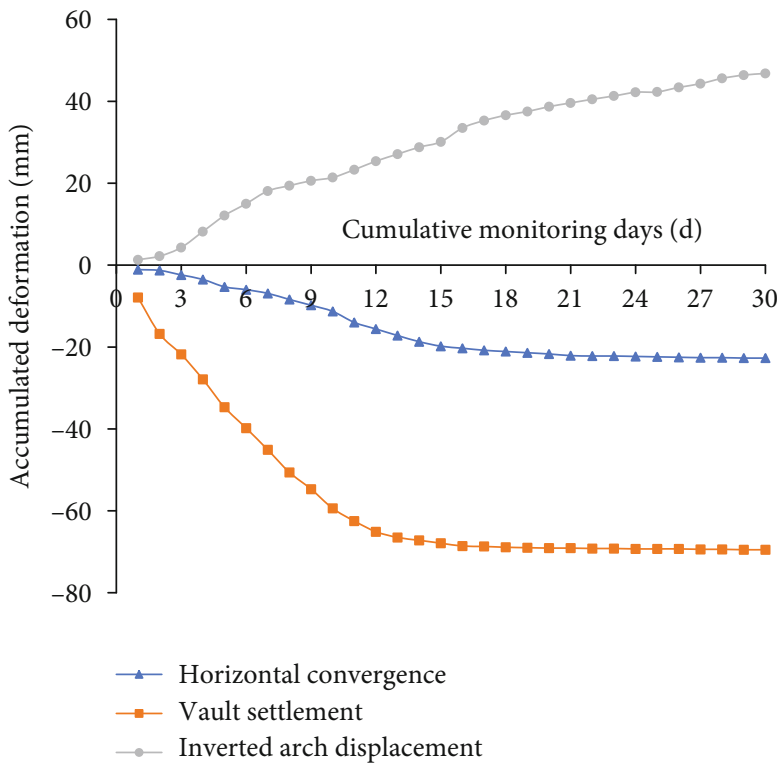

(b) Sections YK280+450 after grouting

FIGURE 12: Deformation aging diagram of surrounding rock of adjacent sections before and after grouting.

settlement, horizontal convergence, and inverted arch displacement reached $67.2 \mathrm{~mm}, 18.7 \mathrm{~mm}$, and $28.8 \mathrm{~mm}$, respectively, after the excavation of the upper step for about 14 days. At this time, the deformation tended to be stable, and the deformation rate gradually decreased. After 22 days, the deformation of surrounding rock is basically stable. After 30 days, the maximum values of vault settlement, horizontal convergence, and inverted arch displacement are $69.5 \mathrm{~mm}$, $22.7 \mathrm{~mm}$, and $46.8 \mathrm{~mm}$, respectively, which fully meet the code deformation requirements. After basement grouting and curtain grouting, the maximum values of vault settlement, horizontal convergence, and inverted arch displacement decrease by $36 \%, 56 \%$, and $71 \%$, respectively, and the time to reach the stable stage is advanced to the 22nd day after tunnel excavation. Obviously, after grouting, the change of surrounding rock displacement field is significantly reduced, which plays a great role in limiting the deformation of the vault and the invert, effectively avoiding the collapse of the vault surrounding rock and the floor heave phenomenon of the invert surrounding rock, and ensuring the construction safety.

4.2. Analysis of Surface Subsidence Deformation. Figure 13 shows the comparison curve of surface settlement deformation before and after basement grouting combined with curtain grouting at adjacent different sections. Obviously, the surface settlement of nongrouting sections YK280+470 is huge after excavation, in which the accumulated surface settlement of the center line of the tunnel reaches $115 \mathrm{~mm}$ after 4 days, and the accumulated surface settlement of $4 \mathrm{~m}$ away from the center line of the tunnel reaches $98.6 \mathrm{~mm}$. This continues to increase, and then the deformation after 18 days in 


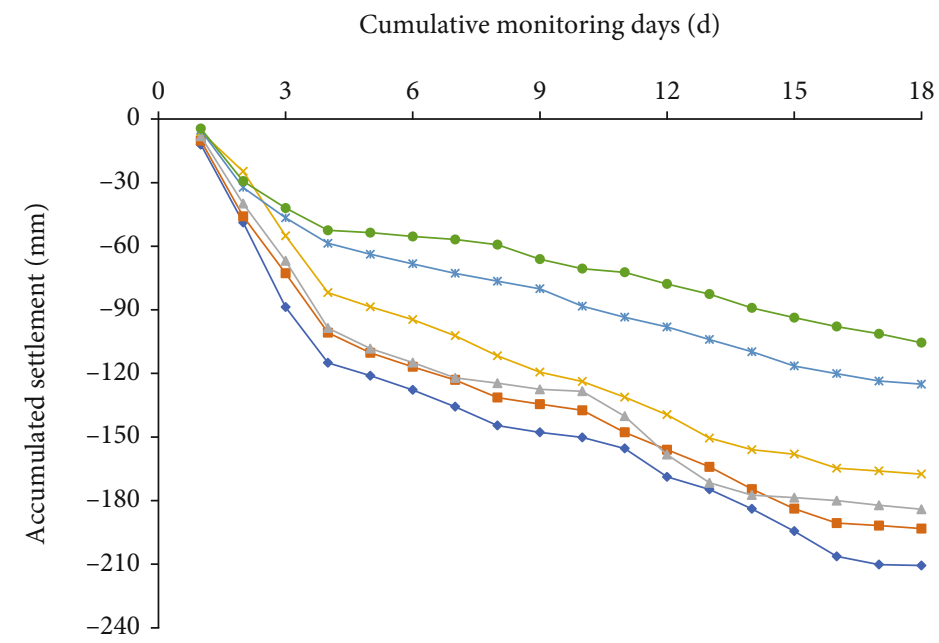

(a) Sections YK280+470 without grouting

Cumulative monitoring days (d)

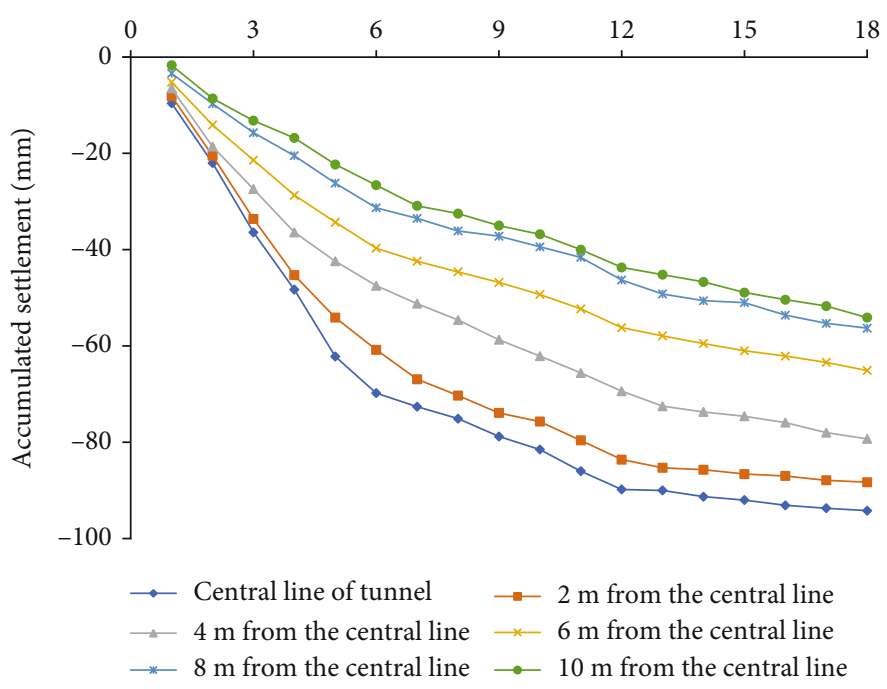

(b) Sections YK280+450 after grouting

FIGURE 13: Surface settlement aging diagram of adjacent sections before and after grouting.

the tunnel central line cumulative settlement is $210.6 \mathrm{~mm}$, and the surface from tunnel center line $6 \mathrm{~m}$ in the surface of the cumulative settlement is $167.5 \mathrm{~mm}$, which is far greater than the allowable value of surface deformation specified in the code [34]. Therefore, it is necessary to take corresponding measures to control the surface settlement after tunnel excavation to prevent surface cracks or collapse disasters.

However, after the excavation of the sections YK280+450 reinforced by basement grouting and curtain grouting, the surface settlement in the affected area of the tunnel is significantly reduced. The accumulated surface settlement of the tunnel center line is reduced to $94.2 \mathrm{~mm}$, which is only $45 \%$ of the accumulated settlement before grouting. Moreover, the surface settlement tends to be stable within $6 \mathrm{~m}$ from the tunnel center line. Basement grouting and curtain grouting can effectively control the surface subsidence of waterrich loess tunnel and reduce or avoid the risk of surface cracks and roof fall.
4.3. Analysis of Surface Transverse Settlement. The development trend of the surface transverse settlement is shown in Figure 14. The surface settlement changes regularly with the construction period. The surface transverse settlement deformation increases sharply within 5 days after excavation of the tunnel face and tends to increase slowly after 15 days. As can be seen from the nongrouting sections YK280+470 in Figure 14(a), with the continuous seepage of groundwater, the surface subsidence of the overlying strata within the tunnel span is obvious. After 5 days of excavation at the tunnel face, the accumulated surface settlement in the tunnel center line reached $127.8 \mathrm{~mm}$, and the maximum value reached $217.3 \mathrm{~mm}$ after 25 days.

Compared with the nongrouting sections, in Figure 14(b), after grouting sections YK280+450, although the overburden strata of the tunnel also presents an overall subsidence phenomenon, due to the reinforcement effect of basement grouting and curtain grouting, the overburden 


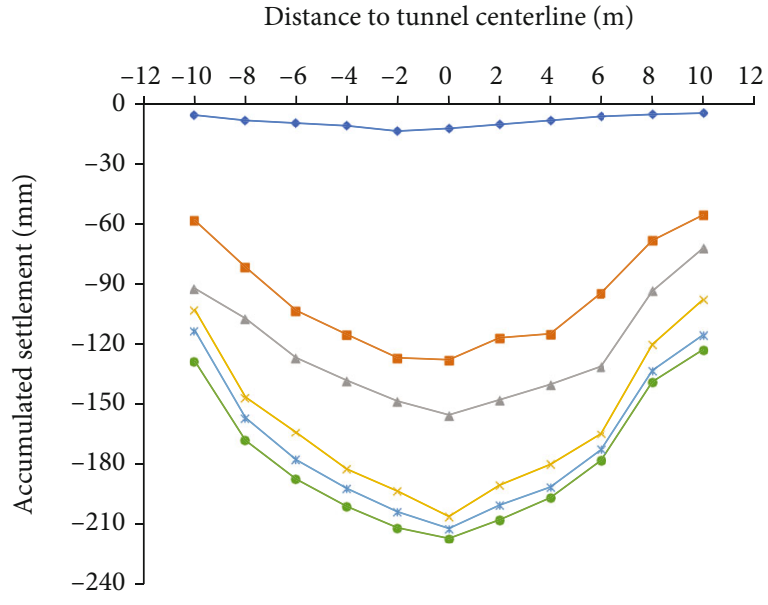

(a) Sections YK280+470 without grouting

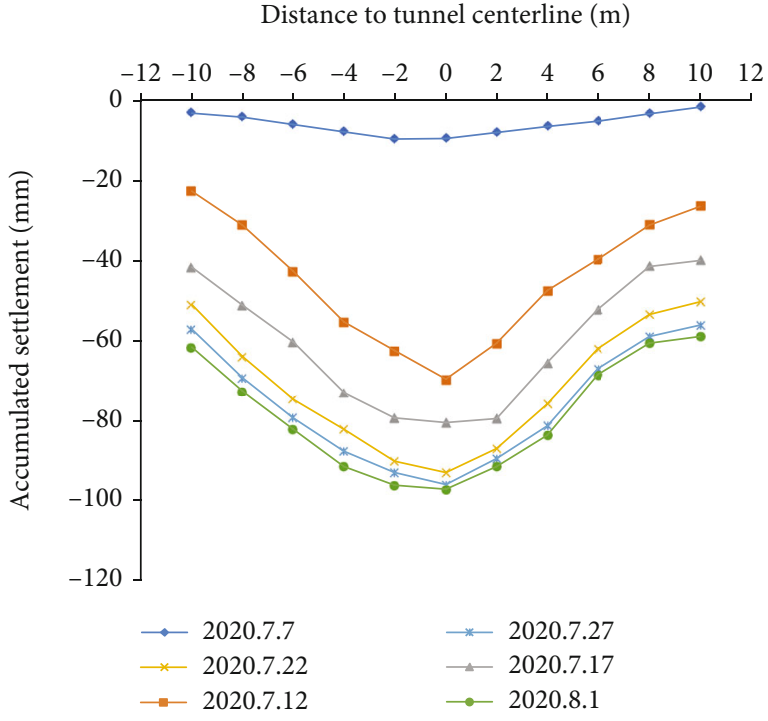

(b) Sections YK280+450 after grouting

FIGURE 14: Development diagram of surface transverse settlement of adjacent sections before and after grouting.

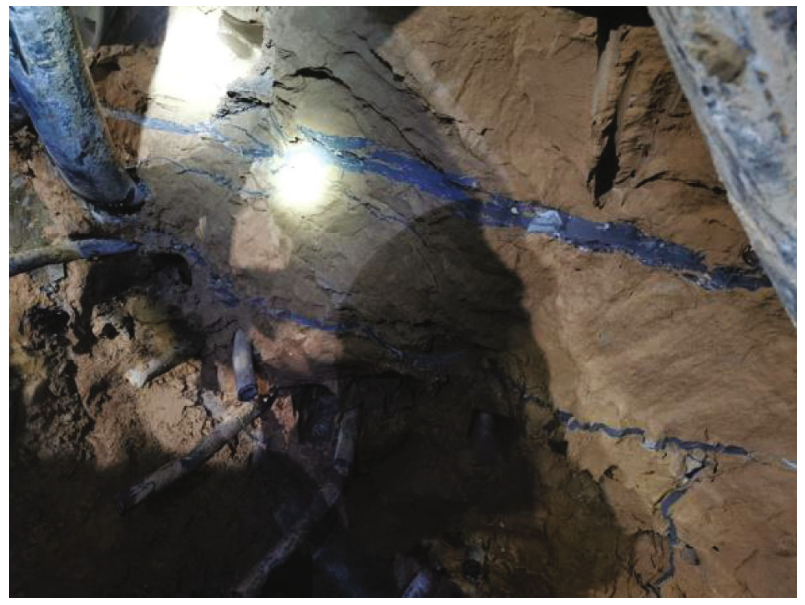

FIGURE 15: Grouting pulp veins.

strata load was effectively dispersed to both sides of the tunnel, and the overburden strata settlement was relatively small within the span of the tunnel. After 5 days of excavation at the tunnel face, the accumulated surface settlement in the middle line is only $69.8 \mathrm{~mm}$. After the surface settlement enters the convergence stage, the influence of tunnel excavation stress release on formation deformation disappears, and the groundwater seepage is not obvious. The cumulative surface subsidence at the center of the tunnel is $97.3 \mathrm{~mm}$, which is about $55 \%$ less than that of the nongrouting sections.

4.4. Field Observation of Grouting Effect. For the soil after grouting reinforcement, after excavation, the slurry diffusion, slurry consolidation, and surrounding rock seepage are observed, so as to effectively evaluate the grouting reinforcement effect and provide important reference for the next cycle grouting design and construction. According to the actual sections of the YK280+450 excavation face, as shown in Figure 15, the soil slurry veins are clearly distributed after excavation, and the slurry is diffused to the whole face. The consolidation strength of the slurry stones is high and hard plastic, the face is dry and has no water seepage, the surrounding rock has no collapse or falling blocks, and the overall stability is good. Curtain grouting technique is effective in strengthening the loess stratum with high moisture content and meets the requirements of tunnel construction.

\section{Conclusions}

(1) Groundwater seepage induced by loess geological conditions and underground water system at the tunnel construction site is the main reason for the collapse accident of the Yulinzi tunnel

(2) It is proposed that the reinforcement method of basement grouting combined with curtain grouting can effectively block the seepage of groundwater and is an effective measure to prevent disasters such as surface cracks, water gushing, mud gushing, and collapse during the tunnel excavation

(3) Basement grouting combined with curtain grouting can effectively control the deformation of surrounding rock and the surface settlement, and the decrease of the deformation of surrounding rock can reach $36 \%-71 \%$, and the decrease of the surface settlement can reach 55\%. After grouting, the deformation of the surface and surrounding rock can be controlled within the allowable value of the code

(4) The slurry-soil combination formed by grouting has obvious compaction effect and supporting effect and can improve the structure of undisturbed loess 
(5) The research results can provide reference for the rapid and safe construction and design of waterrich loess tunnel

\section{Data Availability}

The data used to support the findings of this study are included within the article.

\section{Conflicts of Interest}

The authors declare that they have no conflicts of interest.

\section{Acknowledgments}

The authors gratefully acknowledge the financial support of the Ministry of Education Chang Jiang Scholars Innovation Team (Grant No. IRT_17R51).

\section{References}

[1] J. Qiu, Y. Lu, J. Lai, Y. Zhang, T. Yang, and K. Wang, "Experimental study on the effect of water gushing on loess metro tunnel," Environmental Earth Sciences, vol. 79, no. 11, pp. 119, 2020 .

[2] E. Derbyshire, "Geological hazards in loess terrain, with particular reference to the loess regions of China," Earth-Science Reviews, vol. 54, no. 1-3, pp. 231-260, 2001.

[3] K. Li, Z. Guo, L. Wang, and H. Jiang, "Effect of seepage flow on shields number around a fixed and sagging pipeline," Ocean Engineering, vol. 172, pp. 487-500, 2019.

[4] M. R. Zareifard, "An analytical solution for design of pressure tunnels considering seepage loads," Applied Mathematical Modelling, vol. 62, pp. 62-85, 2018.

[5] Y. Zhang, X. Weng, Z. Song, and Y. Sun, "Modeling of loess soaking induced impacts on a metro tunnel using a water soaking system in centrifuge," Geofluids, vol. 2019, Article ID 5487952, 17 pages, 2019.

[6] W. C. Cheng, G. Li, N. Liu, J. Xu, and S. Horpibulsuk, "Recent massive incidents for subway construction in soft alluvial deposits of Taiwan: a review," Tunnelling and Underground Space Technology, vol. 96, p. 103178, 2020.

[7] X.-X. Liu, S.-L. Shen, A. Zhou, and Y.-S. Xu, "Evaluation of foam conditioning effect on groundwater inflow at tunnel cutting face," International Journal for Numerical and Analytical Methods in Geomechanics, vol. 43, no. 2, pp. 463-481, 2019.

[8] J. Xu, Y. T. Gao, and Z. J. Li, "Application of surface grouting in shallow loess tunnel and the effect analysis," Subgrade Engineering, vol. 4, pp. 190-194, 2014.

[9] G.-H. Zhang, Y.-Y. Jiao, C.-X. Ma, H. Wang, L.-B. Chen, and Z.-C. Tang, "Alteration characteristics of granite contact zone and treatment measures for inrush hazards during tunnel construction - a case study," Engineering Geology, vol. 235, pp. 64$80,2018$.

[10] C. Y. Cao, C. H. Shi, L. M. Peng, and Z. Y. Zheng, "Analysis of deformation controlling law for buildings nearby tunnels with grouting from the ground surface," Journal of Railway Science and Engineering, vol. 6, pp. 59-63, 2013.

[11] Y. X. Wu, S. L. Shen, H. M. Lyu, and A. Zhou, "Analyses of leakage effect of waterproof curtain during excavation dewatering," Journal of Hydrology, vol. 583, 2020.
[12] G. Modoni, L. Wanik, C. M. Maria et al., "Strength of sandy and clayey soils cemented with single and double fluid jet grouting," Soils and Foundations, vol. 59, no. 4, pp. 942-954, 2019.

[13] B. Gong, Y. Jiang, K. Okatsu, X. Wu, J. Teduka, and K. Aoki, "The seepage control of the tunnel excavated in highpressure water condition using multiple times grouting method," Processes, vol. 6, no. 9, p. 159, 2018.

[14] B. Bohloli, O. Skjølsvold, H. Justnes, R. Olsson, E. Grøv, and A. Aarset, "Cements for tunnel grouting - rheology and flow properties tested at different temperatures," Tunnelling and Underground Space Technology, vol. 91, p. 103011, 2019.

[15] G. Zhu, Q. Zhang, R. Liu, J. Bai, W. Li, and X. Feng, "Experimental and numerical study on the permeation grouting diffusion mechanism considering filtration effects," Geofluids, vol. 2021, Article ID 6613990, 11 pages, 2021.

[16] H. Lisa, G. Gunnar, F. Åsa, and N. Tommy, "A statistical grouting decision method based on water pressure tests for the tunnel construction stage - a case study," Tunnelling and Underground Space Technology, vol. 33, pp. 54-62, 2013.

[17] H. Xu, T. B. Li, X. W. Gong, and X. M. Wang, "Study on surface grouting on the karst shallow section of Tongluoshan tunnel," Modern Tunnelling Technology, vol. 5, pp. 44-49, 2008.

[18] C. Wisser, C. E. Augarde, and H. J. Burd, "Numerical modelling of compensation grouting above shallow tunnels," International Journal for Numerical and Analytical Methods in Geomechanics, vol. 29, no. 5, pp. 443-471, 2005.

[19] S. Türkmen and N. Özgüzel, "Grouting a tunnel cave-in from the surface: a case study on Kurtkulağ irrigation tunnel, Turkey," Tunnelling and Underground Space Technology, vol. 18, no. 4, pp. 365-375, 2003.

[20] J.-Q. Liu, K.-V. Yuen, W.-Z. Chen, X.-S. Zhou, and WeiWang, "Grouting for water and mud inrush control in weathered granite tunnel: a case study," Engineering Geology, vol. 279, 2020.

[21] A. Contini, A. Cividini, and G. Gioda, "Numerical evaluation of the surface displacements due to soil grouting and to tunnel excavation," International Journal of Geomechanics, vol. 7, no. 3, pp. 217-226, 2007.

[22] M. Brantberger, H. Stille, and M. Eriksson, "Controlling grout spreading in tunnel grouting - analyses and developments of the GIN-method," Tunnelling and Underground Space Technology, vol. 15, no. 4, pp. 343-352, 2000.

[23] J. Liu, W. Chen, J. Yuan, C. Li, Q. Zhang, and X. Li, “Groundwater control and curtain grouting for tunnel construction in completely weathered granite," Bulletin of Engineering Geology and the Environment, vol. 77, no. 2, pp. 515-531, 2018.

[24] D. Jin, D. Yuan, X. Li, and H. Zheng, "An in-tunnel grouting protection method for excavating twin tunnels beneath an existing tunnel," Tunnelling and Underground Space Technology, vol. 71, pp. 27-35, 2018.

[25] D.-M. Zhang, Z.-K. Huang, R.-L. Wang, J.-Y. Yan, and J. Zhang, "Grouting-based treatment of tunnel settlement: practice in Shanghai," Tunnelling and Underground Space Technology, vol. 80, pp. 181-196, 2018.

[26] B. Stille and G. Gustafson, "A review of the Namntall tunnel project with regard to grouting performance," Tunnelling and Underground Space Technology, vol. 25, no. 4, pp. 346356, 2010.

[27] D. M. Zhang, Z. K. Huang, Z. Y. Yin, L. Z. Ran, and H. W. Huang, "Predicting the grouting effect on leakage-induced 
tunnels and ground response in saturated soils," Tunnelling and Underground Space Technology, vol. 65, pp. 76-90, 2017.

[28] G. Yang, X. Wang, X. Wang, and Y. Cao, “Analyses of seepage problems in a subsea tunnel considering effects of grouting and lining structure," Marine Georesources \& Geotechnology, vol. 34, no. 1, pp. 65-70, 2014.

[29] J. Qiu, H. Liu, J. Lai, H. Lai, J. Chen, and K. Wang, "Investigating the long-term settlement of a tunnel built over improved loessial foundation soil using jet grouting technique," Journal of Performance of Constructed Facilities, vol. 32, no. 5, 2018.

[30] Y. Li, S. Xu, H. Liu, E. Ma, and L. Wang, "Displacement and stress characteristics of tunnel foundation in collapsible loess ground reinforced by jet grouting columns," Advances in Civil Engineering, vol. 2018, Article ID 2352174, 16 pages, 2018.

[31] L. Wang, C. Li, J. Qiu, K. Wang, T. Liu, and H. Li, “Treatment and effect of loess metro tunnel under surrounding pressure and water immersion environment," Geofluids, vol. 2020, Article ID 7868157, 18 pages, 2020.

[32] Y. Zhao, Theory and Method of Tunnel Design, China Communications Press, Beijing, China, 2019.

[33] L. Huang and W. Cai, "Numerical simulation of loess particle effects under different porosity by PFC2D," Chinese Journal of Underground Space and Engineering, vol. 12, no. 4, pp. 11231128, 2016.

[34] Gansu Provincial Standard Compiling Group, Technical Specification for Design and Construction of Highway Tunnel in Loess Area of Gansu (DB62T 4131-2020), Gansu market supervision and Administration Bureau Press, Gansu, China, 2020. 